\title{
Vacina do HPV no Sexo Masculino: Uma Nova Perspetiva no Cancro da Cabeça e Pescoço?
}

\section{HPV Vaccination for Males: A New Perspective on Head and Neck Cancer?}

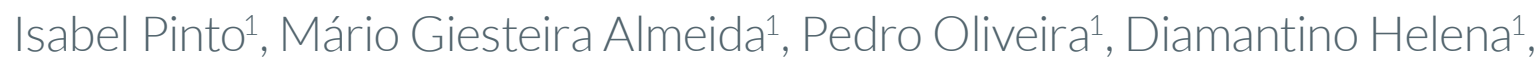
Artur Condé1, João-Firmino Machado²,3

Autor Correspondente/Corresponding Author:

Isabel Pinto [isagomespinto@gmail.com]

\section{RESUMO}

A infeção pelo papilomavírus humano (HPV) é causa necessária para a ocorrência do cancro do colo do útero, mas representa, também, um fator de risco para o desenvolvimento de neoplasias noutras localizações, nomeadamente, cabeça e pescoço. A incidência crescente dos tumores nesta localização, particularmente aqueles associados à infeção por HPV, realçam a importância da implementação de intervenções que permitam a sua prevenção e controlo. Considerando a efetividade da vacina do HPV na redução dos casos de cancro do colo do útero esta poderá desempenhar um papel preventivo nos casos de cancro da cabeça e pescoço HPV positivos.

PALAVRAS-CHAVE: Infeções por Papillomavirus/prevenção e controlo; Masculino; Neoplasias da Cabeça e Pescoço; Vacinas contra Papillomavirus

\section{ABSTRACT}

Infection by human papillomavirus (HPV) is a necessary cause of cervical cancer, although it is also a risk factor for neoplasms on other areas, namely, head and neck. The increasing incidence of tumors in this region highlights the importance of implementing prevention and control interventions. Considering the effectiveness of HPV vaccine in the reduction of cervical cancer cases it may play a role as a preventive strategy for HPV positive head and neck cancers.

KEYWORDS: Head and Neck Neoplasms; Male; Papillomavirus Infections/prevention \& control; Papillomavirus Vaccines 


\section{INTRODUÇÃO}

A infeção pelo papilomavírus humano (HPV) é causa necessária para o desenvolvimento do cancro do colo do útero, mas esta infeção é também fator de risco para a ocorrência de neoplasias em outras localizações, nomeadamente vulva, ânus, pénis, vagina, cabeça e pescoço. ${ }^{1}$

A descoberta da vacina do HPV assim como a sua vasta implementação demonstraram a eficácia da vacina na prevenção primária do cancro do colo do útero, pelo que, nos últimos anos se tem estudado a possível utilidade da vacina na prevenção de cancros associados ao HPV em outras localizações, nomeadamente, no cancro da cabeça e pescoço (CCP).

\section{HPV E CANCRO DA CABEÇA E PESCOÇO}

A associação entre infeção por HPV e cancro da orofaringe está demonstrada, sendo a infeção por este vírus causa suficiente para a ocorrência deste tipo de tumores. ${ }^{2}$ No que respeita ao cancro da cavidade oral a infeção por HPV constitui um fator de risco independente para a ocorrência do mesmo nesta área. ${ }^{3}$ Contudo, o papel exato desta infeção na oncogénese na cavidade oral e, nas restantes localizações da cabeça e pescoço, é ainda desconhecido. ${ }^{3}$

\section{EPIDEMIOLOGIA}

A prevalência global do HPV no cancro da cabeça e pescoço (CCP) é de $26 \%$, contudo, verifica-se que a prevalência do HPV varia conforme a localização anatómica. Cerca de 20\% - 25\% dos tumores da cavidade oral e laringe são HPV positivos, enquanto que $36 \%$ dos casos de cancro da orofaringe (CO) apresentam-se HPV positivos. ${ }^{3-5}$ Contudo, a verdadeira prevalência da infeção poderá ser desconhecida, pois a literatura frequentemente refere apenas oral para as localizações da cavidade oral e orofaringe, sem as distinguir. Uma vez que, apenas a associação e causalidade entre infeção por HPV e CO está demonstrada o presente artigo irá incidir, predominantemente, sobre o cancro nesta localização.

A nível mundial, segundo os dados do Globocan 2018 para ambos os sexos, o CO apresenta uma taxa de incidência padronizada para a idade de 1,1/100 000, com uma taxa de mortalidade padronizada para a idade de 0,57/100 000. Estes valores são superiores quando analisados apenas para o sexo masculino, com uma taxa de incidência padronizada para a idade de 1,8/100 000 (4,5 vezes superior à do sexo feminino) e uma taxa de mortalidade padronizada para a idade de 0,99/100 000 (5,2 vezes superior à observada nas mulheres). ${ }^{6}$

\section{FATORES DE RISCO}

Nas últimas duas décadas verificou-se um rápido aumento da taxa de incidência do CCP associado ao HPV em homens com menos de 50 anos e sem antecedentes de tabagismo e/ou alcoolismo (os fatores de risco classicamente associados a estes tumores). ${ }^{7}$ Analisando apenas a proporção de casos de CO que são HPV positivos, constatou-se um aumento de 50\% nos últimos 20 anos. ${ }^{7}$ Esta variação poderá ser justificada pela mudança dos hábitos sexuais, nomeadamente um maior número de indivíduos praticantes de sexo oral, assim como um maior número de parceiros sexuais. ${ }^{7}$ Por outro lado, verifica-se que o CCP associado ao HPV é também mais frequente no sexo masculino do que no sexo feminino. Esta diferença poderá dever-se a diferenças biológicas entre sexos, mas também ao facto de a infeção genital prévia por HPV nas mulheres poder conferir proteção contra a infeção do epitélio oral por HPV.?

\section{PREVENÇÃO}

Este aumento do número de casos de CCP associados ao HPV deve alertar para a necessidade de desenvolver estratégias que previnam a infeção (prevenção primária), bem como, reforçar a deteção precoce de lesões pré-malignas e de cancro numa fase inicial passível de cura (prevenção secundária). ${ }^{8}$

\section{VACINA DO HPV}

Existem dois tipos de vacinas do HPV: profiláticas e terapêuticas. As vacinas profiláticas disponíveis são a bivalente, quadrivalente e nonavalente e apenas estas estão licenciadas para uso humano. O objetivo deste tipo de vacina é a prevenção da infeção pelo vírus. Estas vacinas deverão ser aplicadas antes do início da atividade sexual, ou seja, antes da exposição ao vírus. As vacinas terapêuticas, ainda em fase de estudo, visam desenvolver respostas imunes capazes de eliminar as células já infetadas pelo vírus. ${ }^{9}$

A vacinação do HPV foi introduzida no Plano Nacional de Vacinação em 2008, sendo atualmente administrada a vacina nonavalente a raparigas com 10 anos. Apesar de em Portugal não existirem, à data, estudos sobre a eficácia da introdução da vacina, estudos realizados em outros países com programas de vacinação (nomeadamente Austrália, Dinamarca, Suécia, Alemanha, Bélgica, EUA e Nova Zelândia) demonstraram a eficácia dos pro- 
gramas de vacinação na redução da infeção persistente e nas lesões de baixo e alto grau nas raparigas vacinadas, assim como, na redução das lesões anogenitais nos parceiros sexuais destas. ${ }^{10}$

Um dos temas de discussão médica mais atuais é o possível benefício de extensão do programa de vacinação ao género masculino. De facto, os homens apresentam risco relevante de desenvolverem múltiplas lesões associadas ao HPV que podem evoluir para cancro. ${ }^{1}$ Por outro lado, nem todos os homens são capazes de beneficiar da imunidade de grupo conferida pela vacinação apenas do género feminino, nomeadamente, homens que têm sexo com homens e homens que têm contactos sexuais com mulheres provenientes de zonas cuja cobertura vacinal é reduzida ou nula. ${ }^{10}$

A vacina quadrivalente demonstrou, em ambos os sexos, imunogenecidade e eficácia elevada na redução de lesões anogenitais percursoras de cancro genital e anal. ${ }^{10}$ Tendo em conta a eficácia da vacina, 16 países (incluindo EUA, Canadá, Austrália, Áustria e Itália) emitiram recomendações oficiais para vacinação universal contra HPV. ${ }^{10}$ Em Portugal, a Comissão de Vacinas da Sociedade de Infeciologia Pediátrica e da Sociedade Portuguesa de Pediatria recomenda a administração da vacina nonavalente, a título individual, a adolescentes do género masculino. ${ }^{10}$

Uma vez que está comprovada a eficácia da vacina na prevenção de lesões anogenitais no género masculino surge a questão do possível papel desta na prevenção de lesões associadas ao HPV em outras localizações como, a cabeça e pescoço. De facto, as vacinas profiláticas desenvolvidas para o cancro do colo do útero poderão ser relevantes na prevenção primária do CCP HPV positivo, dado que o HPV 16 é o genótipo mais frequentemente detetado nestas neoplasias (responsável por 60\% - 80\% dos casos), seguido pelo HPV 18.4,11

A vacinação induz uma forte resposta imunológica com elevada produção de anticorpos anti-HPV ao nível do epitélio oral, motivo pelo qual 88\% dos indivíduos vacinados não apresentaram carga vírica oral detetável para os genótipos incorporados na vacina. ${ }^{12,13}$ Por outro lado, dado que o principal veículo de transmissão da infeção nesta localização é o contacto sexual, ao reduzir a prevalência da infeção genital, a vacinação profilática pode indiretamente reduzir a incidência da infeção oral/ orofaríngea e, portanto, diminuir o risco de desenvolvimento de tumores HPV positivos nestas localizações. ${ }^{5}$ Ou seja, a vacina é capaz de prevenir a infeção de forma direta, mas também, indiretamente.

Uma vez que, muitos países incluíram já no seu programa nacional de vacinação a vacina do HPV no género feminino, as mulheres das gerações mais novas imunizadas ao abrigo destes programas encontram-se, provavelmente, protegidas da infeção oral/orofaríngea por HPV. Contudo, tal como referido previamente, esta vacina não é ainda frequentemente disponibilizada aos homens através destes programas, pelo que, estes não poderão beneficiar diretamente da imunidade conferida por esta ficando, assim, dependentes da imunidade de grupo que poderá não abranger todos os homens. Desta forma, o acesso universal e gratuito à vacina do HPV permitiria prevenir a infeção por HPV em homens e mulheres e, consequentemente, impedir o desenvolvimento das lesões malignas associadas a este vírus. ${ }^{5}$ Contudo, até à data não existem estudos que comprovem a eficácia da vacina profilática na prevenção do CCP.

Na área da prevenção secundária estão a ser desenvolvidos múltiplos ensaios clínicos que parecem apontar para o possível papel da vacina terapêutica como adjuvante no tratamento do CCP HPV positivo. ${ }^{12,14}$

\section{CONCLUSÃO}

A evolução crescente do número de casos de CCP reforça a importância desta patologia e da necessidade de estratégias preventivas, não só dos fatores de risco tradicionais como o álcool e o tabaco, mas também da infeção por HPV. Esta última, poderá ser reduzida através da implementação populacional da vacina do HPV para ambos os sexos.

CONFLITOS DE INTERESSE: Os autores declaram não ter qualquer conflito de interesse na realização do presente trabalho.

FONTES DE FINANCIAMENTO: Não houve qualquer fonte de financiamento na realização do presente trabalho.

PROVENIÊNCIA E REVISÃO POR PARES: Não comissionado; revisão externa por pares.

CONFLICTS OF INTEREST: The authors declare that they have no conflicts of interest.

FINANCIAL SUPPORT: This work has not received any contribution, grant or scholarship.

CONFIDENTIALITY OF DATA: The authors declare that they have followed the protocols of their work center on the publication of data from patients.

PROVENANCE AND PEER REVIEW: Not commissioned; externally peer reviewed. 


\section{REFERÊNCIAS}

1. Zur Hausen H. Papillomaviruses and cancer: from basic studies to clinical application. Nat Rev Cancer. 2002; 2:342-350. doi: 10.1038/nrc798.

2. Gillison ML, Koch WM, Capone RB, Spafford M, Westra WH, Wu L, et al. Evidence for a causal association between human papillomavirus and a subset of head and neck cancers. J Natl Cancer Inst. 2000;3;92:709-20. doi: 10.1093/jnci/92.9.709.

3. Miller CS, Johnstone BM. Human papillomavirus as a risk factor for oral squamous cell carcinoma: a meta-analysis, 19821997. Oral Surg Oral Med Oral Pathol Oral Radiol Endod. 2001;91:622-35. DOI: 10.1067/moe.2001.115392.

4. Lenzi A, Mirone V, Gentile V, Bartoletti R, Ficarra V, Foresta C, et al. Rome Consensus Conference - statement; human papilloma virus diseases in males. BMC Public Health. 2013;13:117. doi: 10.1186/1471-2458-13-117.

5. Kreimer AR. Prospects for prevention of HPV-driven oropharynx cancer. Oral Oncol. 2014;50: 555-9. doi: 10.1016/j. oraloncology.2013.06.007.

6. Globocan 2018 [homepage na Internet]. International Agency for Research on Cancer (IARC) [consultado 2019 Mar 19]. Disponível em: http://gco.iarc.fr/.

7. Sathish N, Wang $X$, Yuan $Y$. Human papillomavirus (HPV)-associated oral Cancers and treatment strategies. J Dent Res. 2014;93(Supl 7):29S-36S. doi: 10.1177/0022034514527969.

8. Cohen N, Fedewa S, Chen AY. Epidemiology and demographics of the head and neck cancer population. Oral Maxillofac Surg Clin North Am. 2018;30:381-95. doi: 10.1016/j. coms.2018.06.001.

9. Nayereh KG, Khadem G. Preventive and therapeutic vaccines against human papillomaviruses associated cervical cancers. Iran J Basic Med Sci. 2012;15:585-601. doi: 10.22038/ijbms.2012.4828.

10. Comissão de Vacinas da Sociedade de Infeciologia Pediátrica e da Sociedade Portuguesa de Pediatria. Recomendações Sobre a Vacinação Contra o Papiloma Vírus Humano no Género Masculino. Acta Pediatr Port. 2018;49:208-13. doi: 10.21069/ APP.2018.14090.

11. Kreimer AR, Clifford GM, Boyle P, Franceschi S. Human papillomavirus types in head and neck squamous cell carcinomas worldwide: a systematic review. Cancer Epidemiol Biomarkers Prev. 2005:14:467-75. doi: 10.1158/1055-9965.EPI-040551.

12. Chaturvedi AK, Graubard BI, Broutian T, Pickard RKL, Tong ZY, Xiao W, et al. Effect of prophylactic human papillomavirus (HPV) vaccination on oral HPV infections among young adults in the United States. J Clin Oncol. 2018;36:262-7. doi: 10.1200/JCO.2017.75.0141.

13. Pinto LA, Kemp TJ, Torres BN, Isaacs-Soriano K, Ingles D, Abrahamsen $\mathrm{M}$, et al. Quadrivalent human papillomavirus (HPV) vaccine induces HPV-Specific antibodies in the oral cavity: results from the Mid-Adult Male Vaccine Trial. J Infect Dis. 2016;15:214-8. doi: 10.1093/infdis/jiw359.

14. Schneider K, Grønhøj C, Hahn CH, von Buchwald C. Therapeutic human papillomavirus vaccines in head and neck cancer: A systematic review of current clinical trials. Vaccine. 2018;45:6594-605. doi: 10.1016/j.vaccine.2018.09.027. 